\title{
End-to-end models for marine ecosystems: Are we on the precipice of a significant advance or just putting lipstick on a pig?
}

\author{
KENNETH A. ROSE \\ Department of Oceanography and Coastal Sciences, 2135 Energy, Coast, and Environment Building, Louisiana State \\ University, Baton Rouge, LA 70803 USA. E-mail: karose@1su.edu
}

\begin{abstract}
SUMMARY: There has been a rapid rise in the development of end-to-end models for marine ecosystems over the past decade. Some reasons for this rise include need for predicting effects of climate change on biota and dissatisfaction with existing models. While the benefits of a well-implemented end-to-end model are straightforward, there are many challenges. In the short term, my view is that the major role of end-to-end models is to push the modelling community forward, and to identify critical data so that these data can be collected now and thus be available for the next generation of end-to-end models. I think we should emulate physicists and build theoretically-oriented models first, and then collect the data. In the long-term, end-to-end models will increase their skill, data collection will catch up, and end-to-end models will move towards site-specific applications with forecasting and management capabilities. One pathway into the future is individual efforts, over-promise, and repackaging of poorly performing component submodels ("lipstick on a pig"). The other pathway is a community-based collaborative effort, with appropriate caution and thoughtfulness, so that the needed improvements are achieved ("significant advance"). The promise of end-to-end modelling is great. We should act now to avoid missing a great opportunity.
\end{abstract}

Keywords: end-to-end, model, climate change, future pathways, community-based, collaborative, interdisciplinary, overpromise, patience, new approaches.

\begin{abstract}
SUMARIO: MODELOS INTEGRALES PARA ECOSISTEMAS MARINOS: ESTAMOS AL BORDE DE UN AVANCE SIGNIFICATIVO O "VISTIENDO LA MONA DE SEDA"? - Durante la última década ha habido un rápido incremento en el desarrollo de modelos integrales para ecosistemas marinos. Las razones incluyen la necesidad de predecir los efectos de cambios globales sobre la biota y la falta de satisfacción con los modelos existentes. Mientras que los beneficios de un modelo integral bien aplicado son claros, hay muchos retos. A corto plazo, mi opinión es que el papel principal de los modelos integrales es hacer avanzar a la comunidad de expertos en modelado, e identificar datos cruciales para el desarrollo de la siguiente generación de estos modelos. Creo que debemos emular a los físicos y construir modelos teóricos primero, para pasar luego a recoger los datos necesarios. Una posible opción para avanzar sería continuar a base de esfuerzos individuales, promesas desproporcionadas, y pequeñas reformulaciones de sub-modelos con escaso potencial ("vestir la mona de seda"). El otro camino es realizar un esfuerzo comunitario de colaboración, con las necesarias reflexiones y precauciones, para que haya avances significativos y se implementen las mejoras necesarias. Las expectativas del modelado integral son grandes. Debemos actuar ahora para evitar perder una gran oportunidad.
\end{abstract}

Palabras clave: integral, modelo, cambio climático, caminos adelante, comunidad, colaboración, interdisciplinariedad, promesas desproporcionadas, paciencia, nuevas aproximaciones.

There has been a rapid rise in the development of end-to-end models over the past decade. The phrase "end-to-end" has become a very popular label to attach to models, and increasingly appears in presenta- tions at conferences and in titles of published papers. While many of these models are deserving of being labelled as end-to-end models, other models resemble old modelling approaches that are being called end-to- 
end to look new or appear up-to-date. Part of the issue is vagueness in what actually constitutes an end-to-end model. Any definition of end-to-end models will involve a continuum and so many models fall in the grey area, with some people considering certain models to be end-to-end models while others do not. Also, the label is being used when the specific modelling to date may not be end-to-end, but the modelling is considered initial steps towards a future end-to-end model. It is therefore important to define what constitutes an endto-end model before I discuss their future.

Travers et al. (2007) described an end-to-end model as one that: (1) aims to represent the entire food web and the associated abiotic environment, (2) requires the integration of physical and biological processes at different scales, (3) implements two-way interaction between ecosystem components, and (4) accounts for the dynamic forcing effect of climate and human impacts at multiple trophic levels. I prefer to expand on this description because some aspects are too vague. In terms of (1), I also require that multiple species or functional groups be represented at each of the key trophic levels and that top predators in the system are included; in terms of (4), I further require that the representation of the physics be such that it can be modified by climate inputs and that the human aspect (e.g. fishery) be represented in a dynamic (state-dependent) manner.

While this, as with any definition, can be criticized, a specific definition helps shape the discussion. What I am trying to do is focus the discussion on dynamic models that attempt to go from climate to people. Thus, adding a single-species fish population dynamics model to the usual hydrodynamics model coupled with a nitrogen-phytoplankton-zooplankton (NPZ) model is not, according to me, an end-to-end model (it lacks sufficient functional groups). Similarly, forcing a NPZ model with time series of water exchanges based on field data is not an end-to-end model (it cannot link back to climate) and neither is a multi-species model that treats harvest as a fixed mortality rate (the human aspect is not dynamic or state-dependent). Of course, I do not own the rights for defining end-to-end models, but it is important to define them here as a basis for further discussion. Some of this is semantics, but sometimes semantics is important for effective communication. I am still bothered when I hear oceanographers refer to NPZ models as "ecosystem models." How can you have an ecosystem model that barely models zooplankton (often included as a closure term for chlorophyll), let alone one that ignores fish and other upper-trophic-level organisms?

A common approach for configuring end-to-end models is to couple existing submodels that represent key components. There have been several recent reviews of existing end-to-end models, which have included existing models with the potential to be end-toend models (Plaganyi 2007, Travers et al. 2007, Rose et al. 2010). Based on my attempt at a strict definition above, more models are included in these reviews than I would consider to truly be end-to-end models. What is striking about these reviews is how end-to-end models to date have been overwhelmingly assembled from existing models, or have been assembled from new components but these new components resemble the general approach taken for the same components in earlier models. Some people have referred to this as a "Frankenmodel" (Mackinson et al. 2009) because the model resembles body parts (components) glued together, as with the monster created in the novel Frankenstein by Mary Shelley. This includes the end-to-end model I am involved with, which couples existing individual-based sardine and anchovy population dynamics submodels with an existing NPZ model called NEMURO, and adds a typical bioeconomics model for the sardine fishery, all within the existing Regional Ocean Model System (ROMS) hydrodynamics model.

In this paper, I first explore the conditions that have led to the accelerating development of end-to-end models (i.e. why now?). I then discuss the potential benefits and challenges. I offer my opinion of the role of end-toend models in the immediate future and in the longerterm, including my vision of how end-to-end models can be successfully used and factors that could hinder their advancement. Finally, I conclude with what I would like see occur over the next few years. We, as the scientific community, are in the formative stages of end-to-end models. We have an opportunity to make end-to-end modelling a significant advance or we can tarnish the approach and set it back by continuing our usual modelling but with a new label (i.e. "You can put lipstick on a pig but it is still a pig").

\section{WHY END-TO-END MODELS NOW?}

There are multiple reasons why end-to-end models are experiencing a recent surge in popularity. These reasons include: (1) a recent emphasis on climateto-fish linkages; (2) recognition of the complexity of marine ecosystem responses to changed conditions; (3) perceived lack of success of traditional fisheries and stock assessment modelling; (4) increasing pressure for tools capable of ecosystem-based fisheries management; (5) a desire, need and demand for something new; (6) technical advances in data collection, physics modelling and fish modelling; (7) increases in computing power; and (8) a general embracing of interdisciplinary research, especially among oceanography, fisheries, and resource economics.

The recognition that marine systems can show complex responses and the need to predict upper-trophiclevel responses to climate change have pushed (or pulled) the modelling community to end-to-end models. I think that, in general, good models must show their merits under perturbed conditions. Models that only act as descriptors of present-day or past conditions are helpful, but more limited in their application than models that can deal with previously unobserved conditions. A major perturbation of the environment 
facing the marine community is climate change and there is great interest in having models, like end-to-end models, that can go from climate up through the ecosystem. There has been much recent interest in forging formal and quantitative linkages between climate and fisheries (e.g. Hollowed et al. 2011, Stock et al. 2011). Unfortunately, it seems that marine ecosystems can show complex responses, which places demands on any modelling designed to predict responses to perturbations such as climate change (Ito et al. 2010). The term "complex" is used here in the mathematical sense (as distinct from complicated) to refer to complex systems theory (Auyang 1999, Railsback 2001); responses are not proportional to the magnitude of changes and the total response is not simply the sum of component responses. Responses are also complex because the mechanisms underlying the response vary in importance among bottom-up, top-down, and waspwaist controls, and these controls can vary spatially and temporally within a system and among systems (Cury et al. 2000).

In parallel with the complexity and climate linkages, there has also been a perceived lack of success of traditional modelling approaches resulting in the desire for something new. There has been much consternation about the low status of many exploited fish populations and how the use of single-species analyses contributed to the problem (Pikitch et al. 2004). While the degree of the failure in fisheries management is debatable (Hilborn 2007, Worm et al. 2009), the perception that past models have failed is real and this leads to pressure for ecosystem-based management and new modelling tools (e.g. Latour et al. 2003). End-to-end modelling seems to offer a new approach, moving away from single-species analysis, that lends itself more to an ecosystem-perspective.

New models, such as end-to-end models, could not even be attempted without sufficient advances in data collection, modelling theory and computing power. Data are collected now with a spatial and temporal resolution never dreamed of 10 years ago. Observing systems and new sensors for synoptic and time series observations of ocean properties are continually being developed, and tagging of upper trophic organisms is providing critical information on movement patterns. In terms of modelling, we now have general three-dimensional hydrodynamics models that are approaching simulation of meso-scale phenomena over multiple decades (e.g. Haidvogel et al. 2008), and the individual-based approach for modelling fish and other upper-trophic-level organisms continues to be popular (DeAngelis and Mooij 2005). We sometimes forget that computing power has shown an almost unbelievable and steady increase. This applies to both desktop computers and high-end parallel machines.

Finally, the science community and research funding agencies have embraced the idea of interdisciplinary research, thus providing encouragement to attempt to develop end-to-end modelling. Some caution is needed here. Interdisciplinary or multidisciplinary is like the label "end-to-end" in that it is sometimes used quite loosely; I have seen examples where three people working on different aspects of nitrogen cycling have called their effort interdisciplinary. However, regardless of the misuse of the term, there has definitely been a real change in the research community towards interdisciplinary research. In particular, the communication taking place now between the disciplines of oceanography and fisheries is almost embarrassing in that such communication seems obvious now and yet was lacking a few decades ago. We are also increasingly seeing attempts to incorporate resource economics and human aspects into quantitative ecological models. All of these act as factors that make the idea of end-to-end models appealing.

\section{BENEFITS AND CHALLENGES}

The benefit of a well-designed and well-implemented end-to-end model is straightforward. An end-to-end model would provide an integrated approach for dealing with complex and complicated ecosystems, and enable a seamless link from climate to nutrients to lower trophic levels to fish to fisheries to people and economics. An end-to-end model could be used for many applications, including the very elusive ecosystem-based management analysis. In many ways, an end-to-end model is the dream of resource managers, whereby they have knobs for key aspects of critical factors that they can turn and then see the responses across many levels of the ecosystem, all in one model.

The challenges that accompany well-designed and well-implemented end-to-end models are significant. Many of the challenges are common to all ecological modelling, but end-to-end modelling amplifies some of these long-standing modelling issues. For example, the difficulties in representing density dependence in the dynamics of upper-trophic-level organisms (Rose et al. 2001) simply become more complicated within an end-to-end model.

The scaling issue is always a problem in modelling and involves deciding what processes and organisms can be ignored and what ones must be represented and in what level of detail. There is no general theory for how to combine processes that operate on different time and space scales together into a model. This is especially true as one goes up the trophic levels, which can make the physics modelling look rigorous. However, there are many decisions related to scale with hydrodynamics modelling as well (e.g. grid resolution, turbulence). I like the description that the lack of a general theory for ecological modelling means that you put 2 modellers in a room and they come out with 3 to 4 models (or an average of 3.5 models). End-to-end models further broaden the organisms and processes for which scaling decisions must be made.

Another issue common to modelling and amplified by end-to-end modelling is focusing the model 
on specific questions. Models must be designed and implemented to address specific questions; otherwise the model will generate inadequate answers for all of the questions. Modelling to answer specific questions becomes especially important for end-to-end models because an end-to-end model can appear to be capable of answering many questions, when in fact a model designed for a specific question would have been configured differently.

There are also several technical aspects that get amplified with end-to-end models that can present new challenges. Trying to couple the multiple components can be difficult and lead to erroneous results that are artefacts of the coupling rather than biological results. Different components can use different mathematics, which can create solution issues. For example, we often use differential equations for the hydrodynamics and difference equations for upper trophic levels, we often have components that operate on different spatial grids and time steps, and we mix Eulerian and Lagrangian methods. End-to-end models tend to be spatially-detailed because of their roots in the physics, and thus how to represent behavioural movement becomes an issue. Modelling behavioural movement is still in its infancy (Nathan 2008), but how it is represented can affect model results (e.g. Wildhaber and Lamberson 2004).

Finally, end-to-end models raise social issues. Effective end-to-end models will require close collaboration between people from multiple disciplines. The usual communication issue of empiricists working with modellers needs to be overcome. In addition, we now have climate, hydrodynamics, lower trophic levels, fisheries, economics, and social sciences all playing major roles in the development of a single unified model. Each of these disciplines has its cultures and ways of doing science and collaborating. End-to-end modelling requires extensive and detailed interactions among the team members during the entire project, so this issue of collaboration across disciplines cannot be simply addressed via email and a few webinars. As with most modelling, and especially end-to-end modelling, the key to success lies in how the details are dealt with, and this requires frequent and intensive interactions among the team members.

\section{ROLE OF END-TO-END MODELS}

In the near-term, I think that the major role of endto-end models is to push the modelling community forward, and to identify critical data so that these data can be collected now and thus be available for the next generation of end-to-end models.

While it seems that the hydrodynamics modelling has made advances in recent years, ecological modelling has become stagnant. This may be because I am an ecological modeller, so other disciplines appear to me to have the veneer of progress, which often reveals itself to be less successful upon close scrutiny. From my perspective, and with no disrespect intended, NPZ and fish models today surprisingly resemble the models from several decades ago. Granted, we have added more compartments to the NPZ models (Friedrichs et al. 2007), we use age-structured stock assessment models for fish that are fitted to data using sophisticated Bayesian approaches (e.g. Martell et al. 2008), and the rise of the individual-based approach (DeAngelis and Mooij 2005) and the widespread use of EwE (Ecopath, Ecosim) software (Pauly et al. 2000) can all be considered significant advances. However, they can be considered as important but incrementally small advances, because the model equations and structure and underlying theory have not changed much. End-to-end models, if pursued properly, can provide a platform upon which ecological modelling can make a significant advance. End-to-end models force dealing with some long-standing issues (scaling) and present some new challenges (such as coupling), which, if successful, would advance the general theory and application of ecological modelling.

End-to-end models can play a major role in influencing future data collection. I think we should act more like physicists and build theoretically-oriented models first, and then collect the data. There will always be people who say there are not enough data; according to some people we would never have enough data to ever build a model. I consider the philosophy that one does not build a model until all of the needed data are available to hinder advances in ecology and marine science. This leads to slow progress and less than optimal data collection, and contributes to the perception that every study area and every species is a unique situation. Of course, some data are needed for theoretical models, but the modelling must be done early in the process of data collection, if not before major data collection takes place. End-to-end models can provide an excellent basis for identifying missing information that is also important to the modelling (i.e. critical data). End-to-end models put all of the data across climate, physics, nutrients, lower trophic level, fish and people together to allow for systematic and consistent evaluation and identification of critical needs.

Presently, and for the short term (the next five years), end-to-end models should be viewed as relatively inaccurate, limited utility for specific management decisions, better used for predicting than for forecasting, and likely more robust when predictions are interpreted on a relative rather than an absolute scale. There is often confusion about the proper interpretation of model results. People often confuse precision and accuracy when using or viewing the results of computer models. Any model developed will be highly precise but will have much lower accuracy. Precision is the exactness of the modelling results, while accuracy is how close the model results are to the truth. Computers, by the nature of their calculations, are very precise; predictions are reported with many digits. It is the model structure (equations) and input values that 
determine accuracy. Stochastic models can further confuse this because they attempt to include quantitative estimates of precision but these are almost always limited to parameter uncertainty (not structural) and lead to arguments about the precision estimates relative to natural variability. Care is needed to ensure that audiences do not confuse the seemingly high precision of deterministic end-to-end models and the likely optimistic and somewhat arbitrary precision of stochastic end-to-end models with high accuracy.

The role of end-to-end models in the short term is neither for forecasting nor for being the primary source for making specific management decisions. I use prediction to mean model results under existing or new conditions. Prediction can be viewed as less tied to real conditions than forecasting. One clear difference is that prediction can be for generalized future conditions, while forecasting would associate specific years to the model results. Forecasting implies that the model results are what we would expect to be observed in the field in that specific year. Thus, predictions are more general (some would say more vague) than forecasts. There is pressure to move ecological models towards forecasting (Clark et al. 2001). End-to-end models are not ready yet for forecasting, and I know of no end-toend model that I would use to set a catch quota for next year. The best role of end-to-end models, until greater skill is demonstrated, is for exploratory analysis and "what-if" scenarios to identify possible future system states and potential unintended consequences that can arise from complex systems.

Model predictions are likely most robust when viewed as relative changes from a model-generated baseline. Absolute results mean that the number of fish predicted by the model is the actual number expected to be observed in the field. Because the ability of end-toend models to resemble present conditions is not well known, interpretation of model predictions is better done in a relative sense. This hinders use of end-to-end model predictions for management because abundance and biomass are important to many management decisions (e.g. setting quotas).

End-to-end models can play a significant role in informing management but also run the risk of being misused and over-sold. End-to-end models can appear to be Nirvana to people and the temptation will be there to use end-to-end models to forecast exceedingly accurate looking numbers and biomasses of key ecosystem groups into the future. If not properly done, this can lead to missteps and disappointments that will hinder further progress. Thus, the objectives and proper usage of the modelling should be clearly stated in order to manage expectations.

In the long-term, end-to-end models will slowly increase their skill, data collection will catch up with the modelling, and end-to-end models will move towards site-specific applications with forecasting abilities. However, managing expectations is also important for the long-term. Issues such as sub-grid scale phenom- ena and the long-standing fisheries recruitment puzzle will not be solved by repacking these issues within end-to-end models. End-to-end models will eventually provide a platform for exploring climate-to-fish-to people links, and allow for more informed long-range planning and management. The key will be patience to allow for steady progress and the needed leap-frogging between advances in modelling and in data collection.

\section{NEXT STEPS}

It is time to evaluate how we are building end-toend models and to develop and address the new or amplified issues associated with end-to-end modelling. In a recent paper, Rose et al. (2010) listed some technical issues that will require some new thinking about the representations we use in end-to-end models. These included: (1) a shift from representing zooplankton as a mortality source on phytoplankton and getting biogeochemistry realistic to simulating zooplankton population and community dynamics as a link between the lower and upper trophic levels; (2) the need to include in models new organisms and processes that we have historically ignored or over-simplified (humans, benthos, macro-invertebrates such as jellyfish, microbial loop); (3) amplification of the long-standing challenge in modelling of how to meld together processes that operate on different temporal and spatial scales; (4) incorporation of acclimation and adaptation by organisms that are possible within multi-decadal simulations and thus could be important under climate change scenarios; (5) considering how to represent the behavioural movement of upper-trophic-level organisms; (6) considering issues related to the software and technology for coding, one-way and two-way solution techniques, and (7) how to assess model performance given the very high data demands of end-to-end models.

Configuring end-to-end models from existing pieces is reasonable as long it is done with careful thought or as an initial step, rather than for convenience. While the temptation is to repackage old models, and we should do so to the extent we utilize what we have learned to date, development of true end-to-end models will require new advances and approaches to address long-standing and emerging issues. I see the next phase of end-to-end modelling as more a series of smaller steps leading to a significant advance. Thus, the phrase "On the precipice of a significant advance" appearing in the title of this paper.

I see two likely alternative extreme paths for the future development and use of end-to-end models. One is the pathway of over-promise, repackaging of poorly performing component submodels, and calling almost anything an end-to-end model ("lipstick on a pig"). The other pathway is a community-based collaborative effort, with appropriate caution and thoughtfulness about how to configure end-to-end models, so that the needed improvements have time to be methodically developed and vetted, thereby allowing for "significant advanc- 
es". I am not suggesting a single model be developed; diversity of approaches from different groups is critical. Rather, the second pathway enables effective communication among the groups and sharing of successes and, equally importantly, failures. The first pathway is easier and might even yield higher short-term benefits (e.g. papers, funding) to some individuals. The second pathway will require investment in the process, likely slower overall progress rate, strong leadership and collaboration, some soul-searching, and a willingness to wait for long-term benefits. The exchange of information and ideas at several recent workshops have been very encouraging (e.g. Rose et al. 2010), and people at the forefront of end-to-end modelling have begun to do the retrospective synthesis that is needed to move forward (e.g. Fulton et al. 2011). With research funding tight, the degree to which we can follow the slower path of collaboration is questionable, as we, like the rest of society, tend to focus on short-term payoffs.

I am proposing we initiate a group effort, which can be loosely organized as needed into subgroups, to provide a forum for end-to-end modelling and associated data collection. A web site is necessary but it alone is not sufficient. Video-conferencing, leveraging opportunities at national and international conferences, and a formal working group or groups are also needed. I see this as an opportunity to further end-to-end modelling, but also as an example of how interdisciplinary and collaborative research can be done in the future. The alternative is for many groups to call their models end-to-end, and to repeat the mistakes of others as we muddle through a mosaic of models without knowing their similarities and differences. I hope that we at least make a sincere effort with the collaborative approach. We also need to give the modelling sufficient incubation time for the data collection to catch up. The most effective and efficient way would be a unified, but not homogenized, community-based effort. The promise of end-to-end modelling is great and the ingredients are rapidly becoming available. I sincerely hope that we use this window of opportunity to truly further the methods and applications of end-to-end modelling. If we do not, end-to-end modelling will likely go the way of other new-sounding methods and tools, and in 10 years or so we will still be calling for new models to address the same long-running issues of linking climate to fish to people. We should act now to avoid missing a great opportunity.

\section{ACKNOWLEDGEMENTS}

Much of the material for this paper is from presentations about end-to-end models that I have made at several workshops and conferences over the past five years. These workshops included the AMEMR and MEECE workshop "Bridging the Gap Between Lower and Higher Trophic Levels" at Plymouth, England in February 2009; the CAMEO Workshop on "End-toEnd Modelling of Marine Ecosystems" held at Woods
Hole Oceanographic Institution in April 2010; and the MARIFISH - ICES Joint Workshop on "Integrated Ecosystem Modelling: Building Our Capacity to Understand and Manage Marine Ecosystems in a Changing World" [WKIEM] held in Barcelona in November 2010. Also, the development of an end-to-end model of sardine and anchovy in the California Current as part of a NOAA CAMEO project (NA09NMF4720183) forced me to recognize and face many of these issues. The opinions expressed in this paper are mine only. I want to acknowledge the important role played by my many collaborators, and participants at the workshops, in the formation of my opinions. In particular, I had many conversations with Enrique Curchitser, Jerome Fiechter, Miguel Bernal, Salvador Lluch-Cota, Bernie Megrey, Shin-ichi Ito, Alan Haynie and Francisco Werner. If this paper is judged brilliant later, then this was a group effort; otherwise, I assume full responsibility for the content of this paper.

\section{REFERENCES}

Auyang S.Y. 1999. Foundations of complex-system theories in economics, evolutionary biology, and statistical physics. Cambridge University Press, Cambridge, UK.

Clark J.S., Carpenter S., Barber M., Collins S., Dobson A., Foley J., Lodge D., Pascual M., Pielke R., Pizer W., Pringle C., Reid W., Rose K., Sala O., Schlesinger W., Wall D. Wear D. 2001. Ecological forecasts: an emerging imperative. Science 293: 657-660.

Cury P., Bakun A., Crawford R. J. M., Jarre-Teichmann A., Quinones R.A., Shannon L. J. Verheye H.M. 2000. Small pelagics in upwelling systems: patterns of interaction and structural changes in "wasp-waist" ecosystems. ICES J. Mar. Sci. 57: 603-618.

DeAngelis D.L., Mooij W.M. 2005. Individual-based modeling of ecological and evolutionary processes. Annu. Rev. Ecol. Evol. S. 36: 147-168.

Friedrichs M.A.M., Dusenberry J., Anderson L., Armstrong R., Chai F., Christian J., Doney S.C., Dunne J., Fujii M., Hood R., McGillicuddy D., Moore K., Schartau M., Sptiz Y. H., Wiggert J. 2007. Assessment of skill and portability in regional marine biogeochemical models: role of multiple phytoplankton groups. J. Geophys. Res. C 112 C08001. DOI: 1029/2006JC003852.

Fulton E.A., Link J.S., Kaplan I.C., Savina-Rolland M., Johnson P., Ainsworth C., Horne P., Gorton R., Gamble R.J., Smith A.D.M. Smith D.C. 2011. Lessons in modelling and management of marine ecosystems: the Atlantis experience. Fish. Fish. 12: 171-188.

Haidvogel D.B., Arango H., Budgell W.P., Cornuelle B.D., Curchitser E., Di Lorenzo E., Fennel K., Geyer W.R., Hermann A.J., Lanerolle L., Levin J., McWilliams J.C., Miller A.J., Moore A.M., Powell T.M., Shchepetkin A.F., Sherwood C.R., Signell R.P., Warner J.C., Wilkin J. 2008. Ocean forecasting in terrainfollowing coordinates: Formulation and skill assessment of the Regional Ocean Modeling System. J. Comput. Phys. 227: 3595-3624.

Hollowed A.B., Barange M., Ito S-I., Kim S., Loeng H. Peck M. (eds.). 2011. Climate change effects on fish and fisheries: forecasting impacts, assessing ecosystem responses, and evaluating management strategies. ICES J. Mar. Sci. 68(6): 983-1372.

Hilborn R. 2007. Reinterpreting the state of fisheries and their management. Ecosystems 10: 1362-1369.

Ito S., Rose K. A., Miller A. J., Drinkwater K., Brander K., Overland J. E., Sundby S., Curchitser E., Hurrell J. W., Yamanaka Y. 2010. Ocean ecosystem responses to future global change scenarios: a way forward. In: Barange M., Field J.G., Harris R.H., Hofmann E., Perry R.I., Werner F. (eds.), Global Change and Marine Ecosystems. Oxford University Press, New York, pp. 287-322. 
Latour R., Brush M.J., Bonzek C.F. 2003. Toward ecosystem-based fisheries management: strategies for multispecies modeling and associated data requirements. Fisheries 28: 10-22.

Mackinson S., Beecham J., Aldridge J. 2009. Frankenstein models? Coupling Ecopath with Ecosim to biogeochemical models. MEECE (Marine Ecosystem Evolution in a Changing Environment) Newsletter 2: 5 .

Martell S.J.D., Pine W.E., Walters C.J. 2008. Parameterizing agestructured models from a fisheries management perspective. Can. J. Fish. Aquat. Sci. 65: 1586-1600.

Nathan R. 2008. An emerging movement ecology paradigm. Proc. Nat. Acad. Sci. 105: 19050-10951.

Pauly D., Christensen V., Walters C. 2000. Ecopath, Ecosim, and Ecospace as tools for evaluating ecosystem impact of fisheries. ICES J. Mar. Sci. 57: 697-706.

Pikitch E.K., Santora C., Babcock E. A., Bakun A., Bonfil R., Conover D.O., Dayton P., Doukakis P., Fluharty D., Heneman B., Houde E.D., Link J., Livingston P.A., Mangel M., McAllister M.K., Pope J., Sainsbury K.J. 2004. Ecosystem-based fishery management science. Science 305: 346-347.

Plaganyi E.E. 2007. Models for an ecosystem approach to fisheries. FAO (Food and Agriculture Organization of the United Nations). Fish. Tech. Pap. 477.

Railsback S. F. 2001. Concepts from complex adaptive systems as a framework for individual-based modelling. Ecol. Model. 139: 47-62.

Rose K.A., Allen J.I., Artioli Y., Barange M., Blackford J., Carlotti F., Cropp R., Daewel U., Edwards K., Flynn K., Hill S.L., HilleRisLambers R., Huse G., Mackinson S., Megrey B., Moll A., Rivkin R., Salihoglu B., Schrum C., Shannon L., Shin Y.-J.,
Smith S.L., Smith C., Solidoro C., St. John M., Zhou M. 2010. End-to-end models for the analysis of marine ecosystems: challenges, issues, and next steps. Mar. Coast. Fish. 2: 115-130.

Rose K.A., Cowan J.H., Winemiller K.O., Myers R.A., Hilborn R. 2001. Compensatory density dependence in fish populations: importance, controversy, understanding, and prognosis. Fish. Fish. 2: 293-327.

Stock C.A., Alexander M.A., Bond N.A., Brander K., Cheung W.W.L., Curchitser E.N., Delworth T.L., Dunne J.P., Griffies S.M., Haltuch M.A., Hare J.A., Hollowed A.B., Lehodey P., Levin S.A., Link J.S., Rose K.A., Rykaczewski R.R., Sarmiento J.L., Stouffer R.J., Schwing F.B., Vecchi G.A., Werner F.E. 2011. On the use of IPCC-class models to assess the impact of climate on living marine resources. Prog. Oceanogr. 88: 1-27.

Travers M., Shin Y.-J., Jennings S., Cury P. 2007. Towards end-toend models for investigating the effects of climate and fishing in marine ecosystems. Prog. Oceanogr. 75: 751-770.

Wildhaber M.L., Lamberson P.J. 2004. Importance of the habitat choice behavior assumed when modeling the effects of food and temperature on fish populations. Ecol. Model. 175: 395-409.

Worm B., Hilborn R., Baum J.K., Branch T.A., Collie J.S., Costello C., Fogarty M.J., Fulton E.A., Hutchings J.A., Jennings S., Jensen O.P., Lotze H.K., Mace P.M., McClanahan T.R., Minto C., Palumbi S.R., Parma A.M., Ricard D., Rosenberg A.A., Watson R., Zeller D. 2009. Rebuilding global fisheries. Science 325: 578-585.

Guest ed.: M. Bernal.

Received January 30, 2012. Accepted February 9, 2012.

Published Online February 20, 2012. 